\title{
Determining the Occurrence of Freshwater in the Aquifers of the Deltaic Formation, Niger Delta Nigeria
}

\author{
Akinwumiju $\mathrm{AS}^{1 *}$ and Orimoogunje $\mathrm{OOI}^{2}$ \\ ${ }^{1}$ Bunmak Systems Limited, Abuja, Nigeria \\ ${ }^{2}$ Department of Geography, Obafemi Awolowo University, Ile-Ife, Nigeria
}

\begin{abstract}
The study attempted to determine the occurrence of freshwater in the aquifers of the Deltaic Formation, Niger Delta Nigeria using Lithologic Logs, Electrical Resistivity and Borehole Parameter (Depth) as input data. The Geographical Information System technique that permit diverse geospatial analyses, modelling and data manipulation and Simple Regression Method that permits the assessment of relationship between two variables were adopted in this study. While the Lithologic Logs were adopted to delineate aquifers and aquitards, the Electrical Resistivity was employed to determine the occurrence of freshwater in the aquifers of the study area. The modelled Geological Sequence revealed that the geology of the study area is very complex and consists mostly of unconsolidated sedimentary materials from top soil to the deep horizon. Hence, all the aquifers have very high storage capacity. It was revealed that the nature of resistivity does significantly increases with depth, which indicates lower level of salinity with increasing depth of hole. The study established positive relationship between depth of hole and aquifer resistivity in $80 \%$ of the sampled locations indicating the occurrence of freshwater in deep aquifers of the study area. The study identified three distinct aquifers (shallow, intermediate and deep) within the Deltaic Formation. The study also emphasized the occurrence of near surface overlying aquitards in the eastern part of the study area, indicating that shallow aquifers of the eastern part are less vulnerable to near surface contamination. Finally, the study concluded that, in most cases, groundwater quality increases as the depth of well increases within the study area. Finally, this study demonstrated the capabilities of Geographic Information System in spatially referenced visualization of hydrogeological characteristics of complex geology.
\end{abstract}

Keywords: Aquifers; Freshwater; Deltaic formation; Niger delta; Nigeria

\section{Introduction}

The increasing demand for potable water in the Riverine areas of Niger Delta has called for the provision of alternatives to the existing insufficient water supply in the region. The attempt to augment surface water supply and rain harvesting, which is of narrow opportunity in the Niger Delta with groundwater has called for a critical groundwater research. The move to develop groundwater in the sub-region has met with pit falls as a result of inadequate hydrogeological feasibility study. In this case, some of the boreholes drilled in the Niger Delta to date have encountered brackish, saline and chloride ion contained water. Thus, this study is stimulated by the inadequate safe water supply coupled with the failure of some boreholes in the Niger Delta.

In the contemporary time, Vertical Electrical Sounding (VES) has been found to be a cost effective and time efficient technique for groundwater exploration in basins of various rock forms. In Nigeria, VES has widely been adopted for groundwater exploration both in regions where groundwater is scarce and places where the incidence of high chloride ion concentration and saline/brackish water intrusion is very common. Interestingly, most of these surveys were conducted by University researchers. Oseji [1] adopted vertical electrical resistivity in order to determine the aquifer systems of Ndokwa Land in Delta state, Nigeria. The study identified 2-4 layers of aquifer with the third and fourth geo-electric layers of the earth. These layers consist of medium to coarse grained sand formations, which have resistivity values ranging from $300 \mathrm{Ohms}$ to $1,500 \mathrm{Ohms}$ and an average thickness of $35 \mathrm{~m}$. The study concluded that aquifers within the study area are mostly unconfined and are very prone to overhead contamination. However, the study revealed that sustainable water supply could be tapped between the depths of $30 \mathrm{~m}$ and $45 \mathrm{~m}$ below the ground surface within the study area. Adepelumi [2] made use of primary sourced surface electrical resistivity data to attempt the delineation of saltwater intrusion into the freshwater aquifer of Lekki Peninsula in Lagos State, Nigeria. The study revealed that there was a dominant trend of decreasing resistivity with depth, which indicates increase in salinity with depth. Also, the study concluded that the variability in resistivity values is associated with the different lithologic types and variations in water saturation. Oteri [3] evaluated saltwater intrusion in the eastern Niger Delta using electric log interpretation. The study revealed the occurrence of some saltwater within freshwater aquifers at the upper zone of Benin Formation between the depth of 30 metres and 947 meters below sea level. The study revealed that there is occurrence of thick freshwater bearing aquifers within the basin, even in areas where many boreholes have been abandoned due to high salinity. The study concluded that the saline water delineated were connate with the sands deposited during some of the transgressive phases of delta formation. Omosuyi [4] adopted vertical electrical sounding using Schlumberger configuration to delineate shallow aquifers in the coastal plain sands of Okitipupa Area in South-western Nigeria. The study delineated two distinct aquifers within the study area. The first aquifer is the shallow (which in most cases is unconfined) that occur between the depths of 5.8

*Corresponding author: Akinwumiju Akinola Shola, Bunmak Systems Limited Abuja, Nigeria, Tel: 2348034445487, E-mail: ojhakin@yahoo.com

Received November 22, 2012; Accepted December 18, 2012; Published December 21, 2012

Citation: Akinwumiju AS, Orimoogunje OOI (2013) Determining the Occurrence of Freshwater in the Aquifers of the Deltaic Formation, Niger Delta Nigeria. J Environ Anal Toxicol 3:162. doi:10.4172/2161-0525.1000162

Copyright: (C) 2013 Akinwumiju AS, et al. This is an open-access article distributed under the terms of the Creative Commons Attribution License, which permits unrestricted use, distribution, and reproduction in any medium, provided the original author and source are credited. 
$\mathrm{m}$ and $61.5 \mathrm{~m}$ below the ground surface. The second aquifer unit is the intermediate (which is mostly confined) that occur between the depths of $32.1 \mathrm{~m}$ and $127.5 \mathrm{~m}$ below the ground surface. The study showed that the aquifers are made up of medium-grained saturated sand with an average resistivity of $296.8 \mathrm{Ohms}$. The study concluded that the occurrence of aquitards above the aquifers of Ajagba, Aiyesan, Agbetu, Ilutitun, Igbotako and Erinji make the aquifers less vulnerable to near surface contaminants than in agbabu, Igbisin, Ugbo and Aboto where aquifers are overlain by less resistive materials. Offodile [5] succeeded in describing the hydrogeological characteristics of the Benin Formation of the Niger Delta and the study concluded that reliable borehole yield can be accessed between the depths of 50 to 120 meters. The study laid much emphasis on the geological formation of the Benin formation. Omosuyi et al. [6] attempted the interpretation of Electromagnetic and Geoelectric Sounding Data for groundwater resources around ObanleObakekere near Akure, South-western Nigeria. The result of the study revealed that the raw real and filtered real amplitudes vary from -30.2 to $45.1 \%$ and -51.8 to $55.0 \%$, respectively. According to this study, structural features of significance to groundwater development were clearly evident in the colour modulated Karous-Hjelt EM sections. The interpretation of the VES data enabled the characterization of three to five geoelectric layers, but three distinct layers, from which aquifer units were delineated. Overburden and bedrock-based aquifer units were delineated across the area. The study revealed that the composite thickness of the overburden/bedrock-based aquifer units varies from $1 \mathrm{~m}$ to $41.6 \mathrm{~m}$ in the area. It was revealed that the aquifer thickness parameters enabled the hydrogeologic zonation of the area into groundwater prospect zones. In this case, areas with thick units are inferred to have higher groundwater prospects while zones with thin aquifer units are believed to have low groundwater prospects. In conclusion, the study emphasized the utility of EM profiling and depth soundings for characterization of local hydrogeology and defines areas suitable for groundwater development. Bello and Makinde [7] adopted Vertical Electrical Sounding techniques to delineate the aquifer of the south-western part of Nupe Basin in Kwara State, Nigeria. The study showed that the layering in the region range from three to five layers. The result of the study suggests that alluvial sand, sandy clay, medium to coarse sandstones and weathered and fractured basement constitute the aquifer found in the sedimentary region. The results of the Vertical Electrical Soundings interpretation indicate that the thickness values of the aquifer vary from $6.01 \mathrm{~m}$ to $58.60 \mathrm{~m}$. The study reveals that the resistivity values of the aquifer components range from 4.2 $\mathrm{Ohms}$ to $106.7 \mathrm{Ohms}$ for the alluvial deposits; $33.7 \mathrm{Ohms}$ to 108.6 Ohms for weathered basement; and $345.7 \mathrm{Ohms}$ to $564.0 \mathrm{Ohms}$ for the fractured rocks. Omosuyi [8] attempted the assessment of groundwater prospect and vulnerability of overburden aquifers at Idanre, Southwestern Nigeria using Electrical Resistivity. The study showed that the thickness of the unconsolidated overburden varies from $0.5 \mathrm{~m}$ to $15.8 \mathrm{~m}$, where about $81.5 \%$ falls within $1-5.9 \mathrm{~m}$ brackets. This showed that unconsolidated materials are generally not significantly thick and hence of apparently lo groundwater prospect. The study revealed that the topmost geoelectric layer has resistivity mostly within the range of $1-100 \mathrm{Ohms}(77 \%)$ across the area. It was revealed that the resistivity values within these brackets tend to indicate silt or clay sequence, which can constitute effective protective geologic barriers for the underlying aquifers. In conclusion, the study suggested that aquifers within the unconsolidated overburden at Idanre are mostly capped by impervious/semi-pervious materials, geologically protecting the underlying aquifers from near-surface contaminants.
Based on critical assessment of the previous studies reviewed above, one can conclude that the geology and the occurrence of groundwater (hydrogeology) in various parts of Nigeria vary heterogeneously as a result of the differential geological and geomorphological histories of various landforms and the underlying rocks. In this regards, variability does exist in the nature of groundwater occurrence in terms of its quantity, quality and characteristics. Also, it is affirmative that Vertical Electrical Sounding has been an effective groundwater exploration tool virtually in all known geological formation in Nigeria. To our knowledge, no study has explored the relationship between the Depth and Resistivity within the study area. Also, we are not aware of any study that combine the scientific strengths of statistical analysis and spatially referenced visualization capabilities to model the occurrence of freshwater in the aquifers of Deltaic Formation. Motivated by the findings of Oteri [9] that resistivity below $10 \mathrm{Ohms}$ represent the presence of saline water while resistivity above $40 \mathrm{Ohms}$ represent the presence of freshwater in the aquifers of Deltaic Formation, resistivity was employed to determine the occurrence of freshwater in the aquifers of the study area. The vertical geological sequence was logged alongside the resistivity to determine the lithology and aquifer resistivity of each borehole. Saltwater was the only contaminant considered in this study due to the recent incessant occurrence of tidal flooding, which would easily contaminate any unconfined aquifer. Thus, shallow unconfined aquifers are considered to be most vulnerable to saltwater intrusion within the study area. Therefore, the trust of this study is to determine the occurrence of freshwater in the aquifers of Deltaic Formation, Niger Delta Nigeria. The specific objectives are to model the geological sequence of the study area; examine the relation between depth of hole and aquifer resistivity within the Deltaic Formation; and appraise the implication of the above on groundwater exploration, development and management within the study area.

\section{Study Area}

The Niger Delta has been growing from Paleocene time (65 million years ago), that is, from the time of the separation of South America from the African continent. The Niger Delta is a fan shaped piece of land which lies between Longitudes $5.30^{\circ} \mathrm{E}$ and $8.30^{\circ} \mathrm{E}$ and Latitudes $4.15^{\circ} \mathrm{N}$ and $5.00^{\circ} \mathrm{N}$. The Niger Delta can be divided into two based on its surface geology and physiography. The Benin Formation (which is the older deposition) covers the upland and the northern part of the delta. The Deltaic Formation (Appendix I) (which is the recent deposition) covers the swampy part of the delta with a dense network of creeks. This is the zone of major oil exploitation activities, characterized by complex environmental condition. This is as a result of its direct contact with Atlantic Ocean, which is a major influencing factor of the basin's environmental condition. The Eastern Deltaic Formation is the focus of this study and all analyses and investigations shall be limited to this sub-region.

\section{Materials and Methods}

Lithologic Logs, Electrical Resistivity and Borehole Parameter (depth) for ten locations within the Eastern Deltaic Formation were obtained from Rivers State Ministry of Water Resources and Shell Petroleum Development Company Limited, both in Port Harcourt, Rivers State Nigeria. These data cover the depths from ground surface to 520 meters below sea level. The selected locations are presented in Appendix II. The lithologic logs were used to model the geological sequence of the study area in ArcGIS 9.2 environment. For the purpose 
of effective comparative analyses of the geological composition, the selected locations were divided into two. The first set (offshore locations) consists of the locations situated at the estuaries while the second set (onshore locations) consists of those locations that are situated at the hinterland and are relatively closer to the Benin Formation. Simple Regression method was adopted to examine the relationship between the depth of hole (independent variable) and aquifer resistivity (dependent variable). The statistical investigation was conducted with the aid of electronic computer using SPSS statistical package.

\section{Results}

The lithologic logs of the study area are presented in Appendixes I, II, III. In the Deltaic Formation, the geological sequence predominantly consists of sandy formation, which is continuous in most cases from the top to the bottom with alternating occurrence of clay and shale layers (Appendix I). In this case, there is occurrence of both confined and unconfined aquifers within the basin. Preliminary studies so far carried out in this region indicates that aquifer resistivity of $40 \mathrm{Ohms}$ and above represent potable water while aquifer resistivity of $10 \mathrm{Ohms}$ and below represent brackish water with chloride ion concentration greater than $550 \mathrm{mg}-1$ [9]. The modelled geological sequence revealed that overlying aquitards of considerable thicknesses occur at various depths between $0 \mathrm{~m}$ and $200 \mathrm{~m}$ below sea level at the onshore locations (Appendix IV). Close observation on the geological sequence of the study area showed that there is occurrence of near-surface thick clay layer towards the Eastern Deltaic Formation (Appendix III). This is obvious in the lithologic logs of Bodo and Opobo where there is occurrence of near-surface thick clay layers at various depths down to 150 meters below sea level. The study revealed that shallow aquifers are mostly unconfined at the offshore locations and in most cases, they bear saltwater. Nevertheless, there exist intermediate and deep aquifers with some overlying thin aquitards at the offshore locations (Appendix $\mathrm{V})$. The study revealed that geological sequence of the study area is made up of unconsolidated sedimentary materials, which is why it is believed that the aquifers of this sub-region have high yield potentials. The occurrence of overlying aquitards at the onshore locations makes the aquifers less vulnerable to overhead contamination than at offshore locations where aquifers are overlain by very thin aquitards that are made up of less resistive materials. This model showed that reliable freshwater bearing aquifers are located in the deep within the basin of the study area. The relationship between the depth of hole and aquifer resistivity down the wells for the ten locations within the study area are presented in Table 1.

The values of regression coefficient (b) for $80 \%$ of the sampled locations indicate positive relationship between the depth of hole and aquifer resistivity. However, the explanations of the regression plains by the relationships are quite significant only for $60 \%$ of the sampled locations. At locations 2 and 9 (Bonny and Oporoma), the values of regression coefficient (b) are 0.04 and 0.01 respectively indicating positive relationships between depth of hole and aquifer resistivity. Nevertheless, the relationships explain $46 \%$ and $32 \%$ of the regression plains, which is not quite significant as a result of the closeness of the $r$ values to zero. At location 6 (Buguma), the value of regression coefficient (b) is -0.49 , indicating a negative relationship between depth of hole and aquifer resistivity. The relationship explains a negative percentage of the regression plain (-1.33\%). Hence, it has been clearly shown that resistivity will be decreasing as depth of hole increases. At location 8 (Odioama), the value of regression coefficient (b) is 0.00 , emphasizing that there is no significant relationship between the depth of hole and aquifer resistivity. The relationship explains a negative percentage of the regression plain, which is very close to zero $(-0.20 \%)$. Here, the resistivity is not dependent on the depth of hole. In this case, the characteristics of the materials and the water in each layer will determine the resistivity of the aquifer regardless of the increase in the depth of hole. The variability of the relationship between the depth of hole and aquifer resistivity among and within various sampled locations can be explained by the heterogeneity of the geological sequence as a result of variations in the nature of sedimentation and deposition, as well as variation in terms of materials deposited at each of the sampled locations. Also, the variation within each of the sampled locations results from the heterogeneity of log characteristics of the soil profile at the locations with three meters interval; that is, the geological sequence of the study area very heterogeneously.

\section{Discussion}

This study revealed that there is occurrence of thick freshwater bearing aquifers in almost all the locations below the depth of 400 meters below sea level. This revelation has earlier been emphasized by Oteri [3]. In contrast to the discovery of Omosuyi [4] in the coastal plain sands of Okitipupa area in South-western Nigeria that aquifers of the coastal area are mostly shallow unconfined and intermediate semiconfined, this study discovered three distinct types of aquifer (shallow, intermediate, deep) within the basin of the study area. Contrary to the findings of Omosuyi [4] that reliable aquifers can be tapped between 5.8 and 127 meters below sea level in the coastal area of South-western Nigeria and Oseji and Offodile $[1,5]$ that reliable aquifers can be tapped between the depths 30-45 meters and 50-120 meters respectively below sea level in the Benin Formation; this study suggested that reliable aquifers can be tapped at or below the depth of 400 meters below sea level. Unlike the occurrence of less thick aquifers in the Basement Complex Rocks as emphasized by Omosuyi et al. and Omosuyi $[6,8]$ in South-western Nigeria, this study revealed that aquifers of the study area are very thick and in most cases saturated. A comparative assessment of the results obtained by Omosuyi [4] and this study showed that water of the aquifers of the coastal area of South-western Nigeria is purer that the water of the aquifers of the Deltaic Formation. It was revealed by this study that resistivity values of the aquifers tapped by all the sampled boreholes were $40 \mathrm{Ohms}$ and above. This result agrees with the conclusion of Oteri [9] that resistivity value that is greater than $40 \mathrm{Ohms}$ indicates the presence of freshwater in a given aquifer within the study area. The study recorded significant trend of increasing resistivity with depth across most of the sampled locations in contrast with the submission of Adepelumi [2] that was carried out on the extreme end of the eastern part of Nigeria's coastal region (Lekki Peninsula). This also points to the fact that the hydrogeology of the coastal region of Nigeria is very complex. The study ascribed the inverse relationship between resistivity and depth of hole at Buguma to the impact of heavy abstraction of groundwater, which usually give way to influx of saline water into the highly porous aquifers. Likewise,

\begin{tabular}{|c|c|c|c|c|c|c|c|c|c|c|}
\hline Location & 1 & 2 & 3 & 4 & 5 & 6 & 7 & 8 & 9 & 10 \\
\hline Settlement & Brass & Bonny & Okrika & Bodo & Opobo & Buguma & Nembe & Odioama & Oporoma & Akassa \\
\hline B & 0.13 & 0.04 & 0.12 & 0.22 & 0.10 & -0.49 & 0.06 & 0.00 & 0.01 & 0.06 \\
\hline $\mathbf{R}^{2}$ & 0.83 & 0.46 & 0.77 & 0.88 & 0.75 & -1.33 & 0.82 & -0.20 & 0.32 & 0.79 \\
\hline
\end{tabular}

Table 1: Relationship between Depth of Hole and Aquifer Resistivity. 
the non-existence of relationship between resistivity and depth of hole at Odioama is attributed to the continuous prevalent influx of saline water into the aquifers from the Atlantic Ocean. Unlike the conclusion drawn by Oteri [3] that the delineated saline water were connate, the occurrence of saline water in the aquifers underlying some settlements that are located on the estuaries result from the continuous alteration of the thermodynamic of the groundwater owing to the reduced volume of upstream river discharge and continuous heavy abstraction of liquid contents from the basin.

\section{Implication}

The nature of the log characteristics that show the stratigraphy of the cretaceous materials are very complex and therefore, show the recent alluvium materials that form the geology are very complex. The implication of this is that aquifers of the study area are highly vulnerable to overhead contamination especially when if they are completely unconfined. The nature of weak correlation values between the depth of hole and aquifer resistivity is an indication that the well resistivity does not substantially increases with depth of hole. This shows that the level of salinity decreases with increasing depth of hole and this actually tallies with major hydrogeological laws. In this case, groundwater of considerable quality could be exploited at great depths within the basin of the study area. All the producing wells of the sampled locations are of great depths, suggesting that they may be expensive in terms of their cost of construction and this is necessary because of the incidence of saltwater intrusion, which prompted that deep aquifers should be located. The implication is that the resource poor inhabitants would not be able to afford the cost of sinking borehole for personal use in the study area. Hence, there is need for the interventions of international donors and government at various levels. The relative low resistivity values recorded for the study area imply that groundwater quality of the Deltaic Formation is relatively low compared to that of the Benin Formation, weathered and fractured zones of the Basement Complex Rock. Finally, positive relationship between depth of hole and aquifer resistivity was recorded for $80 \%$ of the sample locations of which $75 \%$ are very strong (77-88\%). This implies that resistivity increases with increasing depth of hole within the study area. Thus, occurrence of freshwater is expected in the deep confined aquifers of the study area.

\section{Conclusion}

This study adopted Geographic Information System technique and Statistical method to determine the occurrence of freshwater in the aquifers of the Deltaic Formation, using lithologic logs, electrical resistivity and borehole parameter as input data. The study concluded that reliable producing freshwater bearing aquifers would be found at or below the depth of $400 \mathrm{~m} / \mathrm{bsl}$ at any location within the study area. That shallow aquifers are highly vulnerable to contamination and therefore not suitable for development within the study area. The geology of the Deltaic Formation is made up of mostly unconsolidated materials that are highly porous; hence all the aquifers (shallow, intermediate, deep) have very high storage capacity. Aquifers of the eastern part of the study area are less vulnerable to near surface contamination as a result of the occurrence of overlying aquitards of considerable thicknesses. Also, it was concluded that, in most cases, groundwater quality increases as the depth increases within the study area. In addition, this study demonstrate the capabilities of statistical analyses in examining relationship between two parameters and the competence of Geographic Information System in spatially referenced visualization of the hydrogeological characteristics of complex basins.

\section{References}

1. Oseji JO (2010) Aquifer Systems Of Ndokwa Land Delta State, Nigeria. IJRRAS 5: 315-324.

2. Adepelumi AA, Ako BD, Ajayi TR, Afolabi O, Omotoso EJ (2009) Delineation of saltwater intrusion into the freshwater aquifer of Lekki Peninsula, Lagos, Nigeria. Environmental Geology 56: 927-933.

3. Oteri AU (1988) Electric Log Interpretation for the evaluation of salt water intrusion in the eastern Niger Delta. Hydrol Sciences J 33: 19-30.

4. Omosuyi GO, Ojo JS, Olorunfemi MO (2008) Geoelectric Sounding to Delineate Shallow Aquifers in the Coastal Plain Sands of Okitipupa Area, Southwestern Nigeria. PJST 9: 562-577.

5. Offodile ME (1992) An Approach to Groundwater study and Development in Nigeria. Nigeria.

6. Omosuyi GO, Adegoke AO, Adelusi AO (2008) Interpretation of Electromagnetic and Geoelectric Sounding Data for Groundwater Resources around ObanlaObakekere, near Akure, South-western Nigeria. PJST 9: 509-522.

7. Bello AA, Makinde V (2007) Delineation of the Aquifer in the South-western part of the Nupe Basin, Kwara State, Nigeria. Journal of American Science 3: 36-46.

8. Omosuyi GO (2010) Geoelectric Assessment of Groundwater Prospect and Vulnerability of Overburden Aquifers at Idanre, Southwestern Nigeria. OJAS 3: 19-28.

9. Oteri AU (1984) Electric logs for groundwater exploration in the Niger Delta. In: The Challenges in African Hydrology and Water Resources. IAHS. 